\title{
Gesture Controlled Robot
}

\author{
YashDhawan ${ }^{1}$, Rajkumar Saini ${ }^{2}$, Ekta $^{3}$, Ms. Suchita Saxena ${ }^{4}$ \\ ${ }^{123}$ Student, B.Tech. ${ }^{4}$ Assistant Professor, \\ Electronics and Communication Engineering from Moradabad Institute of Technology(MIT), Moradabad.
}

ABSTRACT-: This paper is about a car controlled through gesture based on wireless technology. This aids physically challenged people and additionally for sure tasks educated by human. The aim of this project is to manage the automaton victimization hand gesture. measuring device works according to the hand gestures of the person having gloves containing transmitter and it consists of Arduino Uno for controlling action.

Four main Hand gesture movements like FORWORD, BACKWORD, LEFT and RIGHT area unit detected and enforced.

Keywords: Arduino, Accelerometer, hand gesture, wireless technology, physically challenged.

\section{INTRODUCTION}

People would like to control everything with hands! Sitting on the chair and control things like of a BOSS. thus I finally came out with a hand gesture automaton, which might follow the commands created by hand gestures. Sounds crazy however I promise it's terribly easy. The automaton is based on wireless technology consisting of transmitter and receiver. The transmitter in the gloves sends signals and the receiver works as a detector which detects signals and work according to it. The system is based on master slave architecture i.e. the person having gloves is master and the car is slave.

\section{Block diagram}

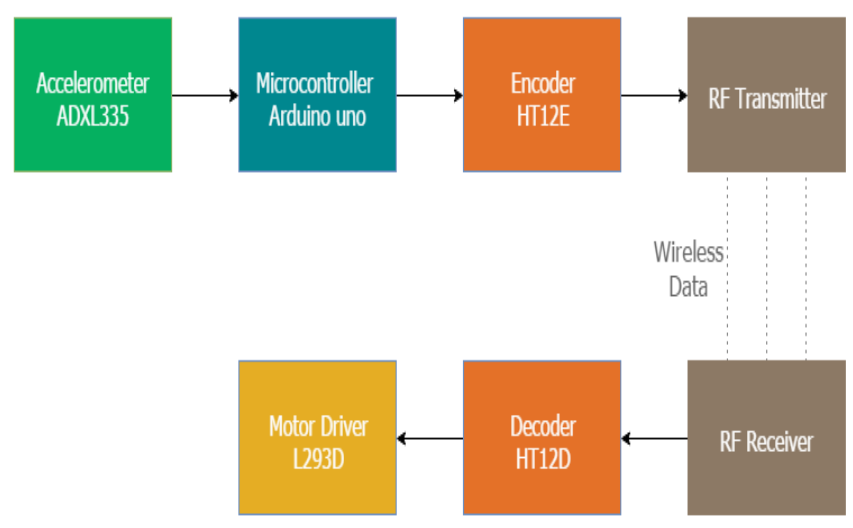

Fig 1.

The above block diagram shows wireless system having transmitter section consisting of accelerometer, Arduino and RF transmitter and the receiver section consisting of RF receiver and motor driver.

\section{III.Components Required}

\author{
ARDUINO UNO \\ ACCELEROMETER
}

GLOVES

RF TRANSMITTER AND RECEIVER MODULE 


\section{MOTOR DRIVER}

BREADBOARD

\section{BATTERY}

CHASIS

BO MOTOR

\section{CASTER WHEEL}

\section{JUMPER WIRES}

In this project,ADXL 335 sensor is used as accelerometer and L293D is used as motor driver.

This project requires 2 arduino uno, 2 breadboards, 2battery and one glove.

The arduino is used to for programming while accelerometer is used to identify the gesture.

To make project wireless, we need RF pair module i.e.

RF Transmitter and RF Receiver module.

\section{IV.FLOW CHART}

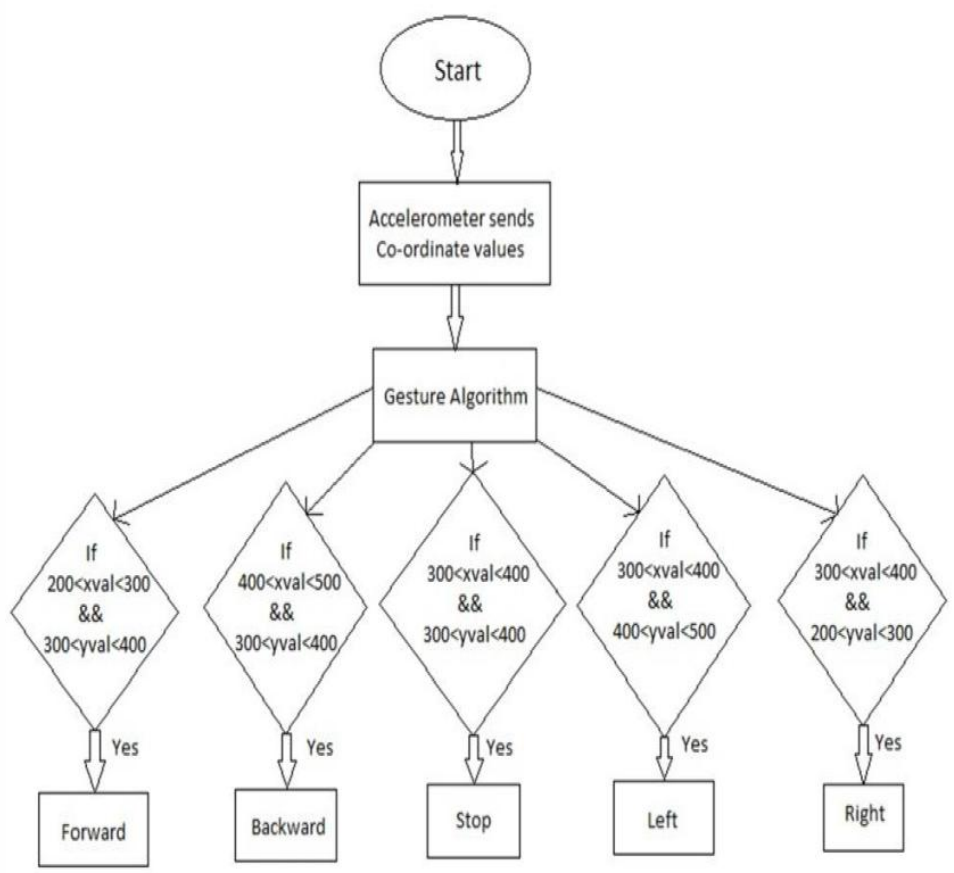

\section{Working}

The overall working principle of the project is showing in the block diagram in figure 1 . The project has mainly consists of two parts one is transmitter section and another is receiver section. In the transmitters section an accelerometer is connected to the Arduino. Based on the gestures value of accelerometer Arduino responds according to it. Those values are then encoded with the help of encoder and transmitted through the RF transmission module connected to it. The receiver section comprises of the RF receiver module, decoder, motor driver and motors. The received values are then decoded with the help of the decoder at the receiver end. According to that the dc motors are controlled through motor driver IC and then the dc motors rotate the wheels according to it. The transmitter is fixed in the hand containing gloves and receiver is fixed in the robotic car vechile. The signals transmitted by transmitter is detected by the detector of the receiver and moves the car according to the gestures. The car moves left if the gesture is in left direction and car moves right if the gesture is in right direction and so on. 
DOI: $\underline{10.51386 / 25815946 / \mathrm{ijsms}-\mathrm{v} 4 \mathrm{i} 3 \mathrm{p} 120}$

\section{Gestures and Implementation}

\section{Forward condition}

When we tilt hand with an accelerometer in front of robot then the robot starts moving forward until the next movement is given.

\section{Backward condition}

When we tilt hand with an accelerometer in backward direction then the robot starts moving in backward direction.

\section{Right condition}

When we tilt hand with an accelerometer in right side then the robot moves in right side until next command is given.

\section{Left condition}

When we tilt hand with an accelerometer in left side then the robot starts moving in left direction until next signal is given.

Stop condition

When we keep hand with an accelerometer in stable position then robot becomes stop until next command is given.

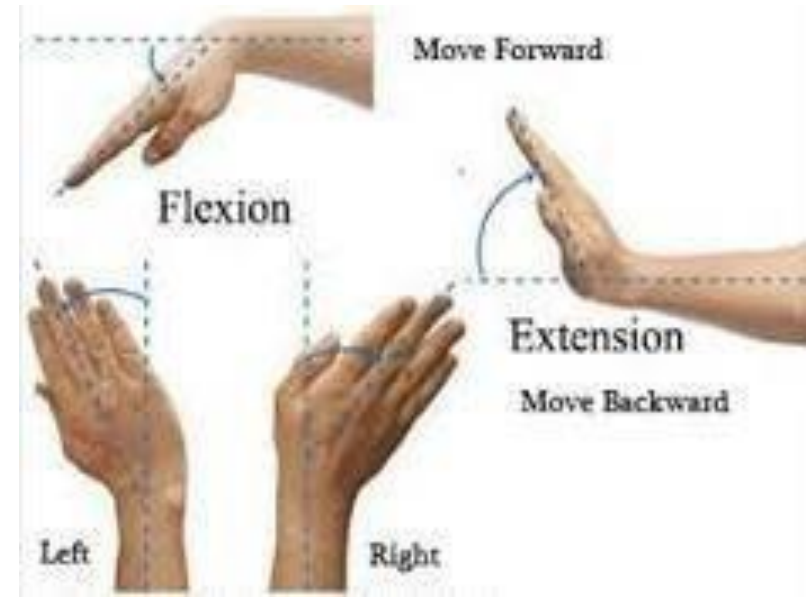

\section{Applications}

1- Gesture controlled robots can be used for patients having paralysis.

2- Gesture controlled robots are helpful in military.

3- Gesture controlled robots can be used for entertainment purposes for making the game more interactive.

4- Gesture controlled robots is helpful for handicapped and physically disabled people to achieve certain tasks such as driving a vechile.

5- Construction field

6- In industries to control trolley and lift.

\section{Conclusion}

This project is used for a hand gesture based wireless medical assistance system for physically challenged people with Arduino. .Results of the system designed are also discussed in details. Based on the gesture of the hand the motors of the medical assistance system can be controlled in different directions. The above system is not only help in medical field but it is also used in military. It is also useful in many industries. With the help 
DOI: $\underline{10.51386 / 25815946 / \text { ijsms-v4i3p120 }}$

of this project many physically challenged people live their life happily and the busy people can easily do their work. Many industries are able to take advantages and military can also take benefit from it.

\section{REFERENCES}

[1] R. K. Megalingam, S. Sreekanth, A. Govardhan, C. R. Teja and A. Raj, "Wireless gesture controlled wheelchair," 2017 4th International Conference on Advanced Computing and Communication Systems (ICACCS), Coimbatore, 2017, pp. 1-5.

[2] Seong-Pal Kang and J. Katupitiya, "A hand gesture controlled semi-autonomous wheelchair," 2004 IEEE/RSJ International Conference on Intelligent Robots and Systems (IROS) (IEEE Cat. No.04CH37566), 2004, pp. 3565- 3570 vol.4.

[3] Vishal V. Pande, Nikita S.Ubale, Darshana P. Masurkar, Nikita R. Ingole, Pragati P. Mane "Hand Gesture Based Wheelchair Movement Control for Disabled Person Using MEMS.”Int. Journal of Engineering Research and Applications , ISSN : 22489622 , Vol. 4, Issue ( Version ), April 2014, pp.152 158.

[4] Amundson J.S, Amundson S.G, “A joystick controlled

[5] wheelchair", Biomedical SciInstrum .1991; 27:131-3.

[6] O. Mirabella, M. Brischetto, G. Mastroeni “MEMS based gesture recognition”, proceedings .HSI P.599 - 604, May 2010.

[7] https://www.digchip.com/datasheets/parts/datasheet/1848/LILYPAD-pdf.php

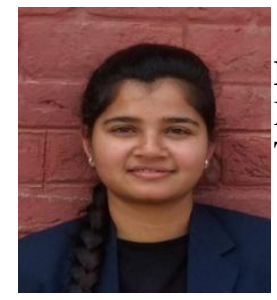

Ekta is pursuing(doing) the B.Tech. in Electronics and Communication Engineering from Moradabad Institute of Technology(MIT), Moradabad. Areas of interest includes Telecommunication and Internet of Things.

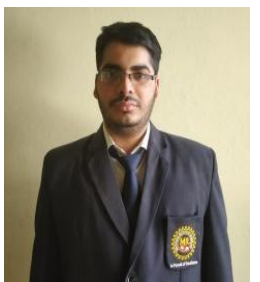

Yash Dhawanis pursuing(doing) B.Tech. in Electronics and Communication Engineering from Moradabad Institute of Technology, Moradabad. Interested fields areMicrocontrollers and Robotics.

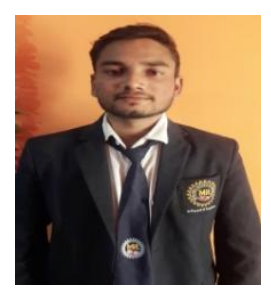

Raj Kumar Sainiis pursuing(doing) B.Tech. in Electronics and Communication Engineering from Moradabad Institute of Technology, Moradabad. Area of interest includes Wireless Sensors and IOT.

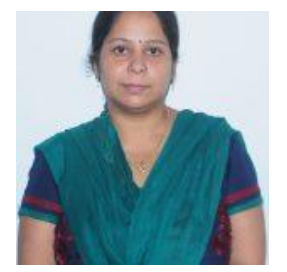

Shucita Saxena is currently working as an Assistant Professor in Moradabad Institute of Technology. Her current research area are Optical Network,Neural Technology and Embedded System. 